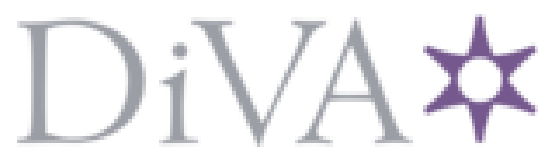

http://www.diva-portal.org

This is the published version of a paper published in Sport Science Review.

Citation for the original published paper (version of record):

Meckbach, J., Gibbs, B., Almqvist, J., Quennerstedt, M. (2014)

Wii Teach Movement Qualities in Physical Education.

Sport Science Review, 23(5-6): 241-266

http://dx.doi.org/10.1515/ssr-2015-0004

Access to the published version may require subscription.

N.B. When citing this work, cite the original published paper.

Permanent link to this version:

http://urn.kb.se/resolve?urn=urn:nbn:se:oru:diva-39989 


\title{
Wii Teach Movement Qualities in Physical Education
}

\author{
Jane MECKBACH${ }^{1} \bullet$ Béatrice $\mathrm{GIBBS}^{2,4} \bullet \mathrm{Jonas} \mathrm{ALMQVIST}^{3}$ \\ Mikael QUENNERSTEDT ${ }^{4}$
}

I

n Sweden, the PE curriculum states that students are expected to develop a number of abilities, a variety of movement activities and qualities. Interesting to explore is then if exergames (video games that includes physical activity) can be seen as a teaching resource to learn different movement's qualities. With a new teaching tool that has been introduced in education and new policy documents emphasising development of different movement qualities, the purpose of this article is accordingly to investigate students' use of different movement qualities when playing various exergames during PE. For this we use a version of Laban Movement Analysis (LMA) adapted for exploring exergames in PE practice. The empirical data include video-recordings from $\mathrm{PE}$ lessons. The games offered were of three different characters; sports games, exercise games and dance games. We are inspired by the LMA framework and explore students' movement qualities on the basis of four aspects; body, effort, space and relations. Further, with socio-cultural learning theory, recognition of artefacts, other people and the offered content of the exergames are also involved in the analysis. Our findings show that exergames are creating opportunities for PE teachers and students to pay attention to different movement qualities. In PE the player is accordingly involved in a complex context of movement qualities, interacting with the game and with other students.

Keywords: artefact, exergames, physical education, movement qualities, Laban movement framework, movement analysis chart

\footnotetext{
1 The Swedish School of Sport and Health Sciences, GIH, Stockholm, Sweden

Fredrika Bremergymnasiet, Stockholm, Sweden

Uppsala University, Sweden

${ }^{4}$ School of Health and Medical Sciences, Örebro University, Sweden
} 


\section{Introduction}

Exergames are a form of video-game that inspires and encourages the player to be physically active in order to play the game. Unlike previous perceptions of video games as a sedentary activity, these games provide both entertainment and competition in the form of movement and physical activity. These games have become popular with many young people and can according to many scholars (e.g. Graf et al., 2009; Gao et al., 2013) provide an attractive option for promoting a healthy lifestyle while at the same time connecting to the lives of young people today. Schools in a number of countries (e.g. Australia, Canada, the United States and Sweden) currently use exergames as a teaching tool in physical education (PE) to encourage young people to be more physically active (Quennerstedt et al., 2013). According to several researchers, the games thus create new opportunities for teachers and students to increase physical activity as an alternative activity in PE (Papastergiou, 2009; Ennis, 2013; Meckbach et al., 2013).

Research in this field has mainly focused on the physical, psychological and some extent social benefits of exergaming (Sheehan \& Katz, 2013; Gao, Zhang \& Stodden, 2013; Sun, 2013). Ennis (2013, 153), however, maintains that 'exergaming can make contributions to PA, situational interest, motivation to participate in PE, and enjoyment,' but also adds that educational questions about body movements and movement qualities should be raised when a new teaching tool such as exergames is introduced in schools.

Educational researchers have for a long time focused on PE in schools in terms of, for example, objectives and content (e.g. Amade-Escot, 2000; Chen \& Ennis, 2004), health (e.g. Gard \& Wright, 2001; Webb et al., 2008), gender (e.g. Gard, 2006; Fagrell et al., 2012), attitudes to physical activity (e.g. Silverman \& Subramanian, 1999), co-education or special instruction (Paechter \& Head, 1996; Meckbach \& Söderström, 2002) and education of the body (Kirk, 2001; Whitehead, 2007; Azzarito \& Solomon, 2006; Larsson \& Quennerstedt, 2012). However, in contrast to studies of movement in terms of children's motor development (cf. Wallian \& Chang, 2006) few studies in education have focused on the teaching of movements, particularly in relation to the teaching tools and artefacts used in PE practice (cf. Hayes \& Silberman, 2007; Quennerstedt, Almqvist \& Öhman, 2012; Ennis, 2013). The same goes for PE in schools where teachers often uncritically use and introduce different kinds of sports equipment and other artefacts without necessarily reflecting over the educational value (Quennerstedt et al., 2012). The questions are what exergames should solve in PE practice, and how does exergames go beyond being just another 'throwing in the ball' in PE? 
The context of this study is Swedish PE and in relation to the teaching of movement in PE in Swedish schools, the latest curriculum lays down clear objectives. Children in compulsory school are to be afforded the opportunity to develop abilities, one of which is to 'move without restriction in different physical contexts' (the Swedish National Agency for Education, 2011, 51). The teaching in PE should also provide many different kinds of movement activities and qualities, and against this background we aim to investigate what a new teaching tool, namely exergames, has to offer in this context. The purpose of this article is accordingly to investigate students' use of different movement qualities when playing various exergames during PE. For this we use a version of Laban Movement Analysis (LMA) adapted for exploring exergames in PE practice. However, first we need to say something about what research says about the use of exergames as a teaching tool in schools.

Exergames as a teaching aid. For many years, there has been a perception that the increasing prevalence of video games is a contributing factor to rising obesity and falling levels of physical activity among young people (Carvalhal et al., 2007; Meckbach et al., 2013), and the games are seen as mindless and violent forms of entertainment (Hayes \& Silberman, 2007). However, with the introduction of sports games, exercise games and dance games, so called exergames, this scenario has in many ways changed.

Since the beginning of the twenty-first century, a number of studies have focused on exergames and their effects. Studies on exergaming students show that their self-esteem, classroom behaviour and social skills improve and they become more involved and interested in sport, dance and PE lessons than before, feel more coordinated and less short of breath (Sashek, 2004; Brubaker, 2006). Also studies show that the effects of exergaming are increased fitness (Unnithan, Houser \& Fernhall, 2006), weight loss (Ni Mhurchu et al., 2008; Guy, Ratzki-Leewing \& Gwadry-Sridhar, 2011), increased motivation (Gao, Zhang \& Stodden, 2013) and low and moderate physical activity levels with physical intensity increasing over time (Sun, 2013). However, Sun's study (2013) indicates that, despite the stimulating environment in which the students were playing different exergames, their interest waned over a twelve-month period.

Other studies which have compared playing different exergames with more traditional PE lessons show that the video games help students become more physically active (Ni Mhurchu et al., 2008; Maddison et al., 2009; Fogel et al., 2010; Biddiss \& Irwin, 2010); develop more confidence in, and a more positive relationship to, physical activity (Lwin \& Malik, 2012); and also greater motivation to take part in PE and increased enjoyment (Sun, 2013). A study comparing dance games and aerobic dance in PE shows that enjoyment and motivation 
are greater when playing dance games (Gao, Zhang \& Stodden, 2013); however, unlike earlier studies, this one maintains that the physical activity level is greater during the aerobic dance lessons. Research thus shows that exergames produce physical, psychological and sometimes even social benefits.

There are also a few critical scholarly voices in relation to the use of exergames in school. Song, Peng and Lee (2011) report that seeing yourself as an avatar on the screen has a positive impact if you are satisfied with your body image, but has a negative impact if you are unhappy about your body. Millington (2009) and Öhman et al. (2014) criticises how games like Wii fit tend to be regarded as fitness experts prescribing what an ideal body is. In this supervision of students' bodies, the games use measurement of balance, Body Mass Index (BMI) and chronological age as determinants of normal bodies and good health. Millington (2009) as well as Vander Schee and Boyles (2010) further argue that bodily knowledge in this way becomes politicised in terms of risk, and that nonconformity from a measurable normality is something that must be corrected.

Ennis (2013) asserts that the games should be seen not only as a reason and opportunity for physical activity, but also as an opportunity to increase students' learning, i.e. she believes that increasing students' enjoyment and improving their perception of PE and the activities involved are key to creating more meaningful experiences (Ennis, 2006). However, we know very little about how artefacts influence PE practice, and few studies have focused on learning and artefacts, such as exergames (cf. Heath, Hindmarsh \& Luff, 2010; Quennerstedt, Almqvist \& Öhman, 2011). The studies on learning and exergames that exist show that exergames can be used to improve spatial (DeLisi \& Wolford ,2002) and motor skills (Fery \& Ponserre, 2001), balance (Sheehan \& Katz, 2013) and problem-solving skills (Ko, 2002). Young et al. (2012) point out that exergames can have positive effects on students' learning, stemming from their involvement, motivation, and mastery of the content and continued interest in the subject. Papastergiou (2009: 603) states that the games can have 'potential benefits as educational tools for $\mathrm{HE}$ and PE, and that those games may improve young people's knowledge, skills, attitudes and behaviours in relation to health and physical exercise'.

Hayes and Silberman $(2007,20)$ maintain that what is unique about exergaming is it 'allows players to experience immediate and often unpredictable consequences from their actions', i.e. the players gain a bodily understanding of the physical activity they are doing in that the game gives direct feedback. They show that exergames allow the player to study how the avatar performs what might for him or her be new dance steps so they can be mimicked repeatedly while receiving feedback and eventually mastering them (Hayes \& Silberman, 2007). 
This review of the research shows that studies on exergames deal principally with their physiological and psychological effects, and few have examined the use of artefacts and learning as an educational question. It also shows that the research community is quite positive towards using exergames in schools, but also that there are some critical voices.

Exploring movement qualities in exergaming. In many English-speaking countries, Laban Movement Analysis (LMA) has served as the basis for steering documents, lesson content and the observation of students' movements, where, for example, the teacher and students note the latter's movement qualities and expressions using observation charts (Murray \& Lathrop, 2005; Langton, 2007). In Sweden for example that have not been so. Previous research has used LMA to analyse students' movements in various movement activities both with and without teaching equipment. However, no study has yet employed this analytical tool for students specifically using interactive equipment.

With regard to analysis of students' movements, in order to know what should be observed, analysed and described and how this can be done, it is helpful to use a movement framework (cf. Allison, 1990; Nyberg \& Larsson, 2012). Skoning (2008) argues that Laban's movement framework is simple to use for observing, analysing and describing students' movements. This movement framework has also been used as an observation tool in a number of research fields, such as therapy (Parteli, 1995), industrial (Vasey et al., 2006), medical (Foroud \& Whishaw, 2006) and, above all, dance research (Levy \& Duke, 2003; Swaminathan et al., 2009; Lepczyk, 2011).

Several researchers have also been inspired by and further developed LMA, especially in PE in English-speaking countries, in order to observe students' movements (cf. Murray \& Lathrop, 2005; Langton, 2007; Weiller-Abels \& Bridges, 2011). The movement analysis framework is based on four categories: body, space, effort, and relationship. Our study has been inspired by this movement framework, where concepts have been developed to describe movements and the quality of their execution and from that we have created a movement analysis chart.

The movement analysis chart is accordingly based on LMA in order to study movement qualities but modified for the use of analysis of exergaming inspired by Murray and Lathrop (2005), Langton (2007) and Weiller-Abels and Bridges (2011). By movement qualities we, in line with Laban (1988) mean the charachteristic of the movements, and not if the movements are better or worse, good or bad. Since movement in PE using exergames are dependent on both the artefact and the social context we are also inspired in our analysis by sociocultural ideas (Quennerstedt et al., 2012), on the basis that during PE- 
lessons students interact with each other as well as with artefacts. Ennis (2013) states, that a player not only experiences the game alone but constantly interact with the game, their friends and their teacher. She thus believes that the player is placed in a complex environment where he or she interacts with the game and with others in an educational context implicit in PE (Ennis, 2013). We have therefore chosen to study the students' movements when they interact with the exergames individually and when two or more interact with each other and with the exergames. This involves looking at the movement in context, particularly in the space and the relationship categories.

The body category focuses on what the students' bodies do when they play exergames, in terms of their body parts, body actions and body shapes. The space category deals with where in space the movements are performed. The effort category refers to how the body moves. Finally, the relationship category concentrates on with whom or with what the moving body relates, see Table 1.

Table 1

\section{Movement Analysis Chart}

Body (what)

- body parts (arms, legs, trunk)

- body actions (balance, weight transfer, flight, rotation, stepping, jumping)

Description:

- body shapes (extend, bend, twist, swing)

Space (where)

- space (personal, general)

- direction (forwards, backwards, up, down, sideways, round)

- pathway (straight, circular, curved, zigzag)

Description:

- extension (wide, narrow, long, short)

- level (high, medium, low)

- plane (frontal, horizontal, sagittal)

\section{Effort (how)}

- time (from sudden to sustained)

- weight (from light to strong)

- space (from direct to indirect)

Description:

- flow (from bound to free)

\section{Relationship (with whom and with what)}

- with others (in front of, behind, far from, close to, over, under, towards, away from) Description:

- with exergames (far from, close to, copy, contrast, competing, practising)

Note: Modified from and inspired by Murray and Lathrop (2005), Langton (2007) and WeillerAbels and Bridges (2011). 
The body category deals with what the students' bodies do when they move during the various games. This category is based on three dimensions: body parts, what the arms, legs and trunk do; body actions, what the body does in terms of balance, weight transfer, flight, rotation, stepping and/or jumping; and body shape, taking the concepts stretch, extend, twist and swing as its starting points.

The space category involves where and in what direction the students' movements take place. This category is based on six dimensions: whether the movement occurs in the personal or general space; in which direction the movement happens, focusing on forwards, backwards, upwards, downwards, sideways and/ or round; in which pathway does the movement occur, i.e. straight, circular, curved or zigzag; what is the extension of the movement, namely how wide (far from the body) or narrow (close to the body) or how long or short; at what level is the movement executed, high (as high as the arms can reach) medium and/or low (movement on the ground); and in which plane the movement occurs: the frontal, sagittal or horizontal.

The effort category deals with how the students' movements take place and describes their character and style. This category is based on four dimensions, each with opposing poles, namely time, that is, whether movements are sudden (quick, explosive, staccato) or sustained (slow, relaxed and legato); weight, how light (airy, faint, and indistinct) or strong (powerful, firm and clear) a movement is; space, how direct (straight, distinct) or indirect (wavy, scattered) a movement is; and flow, how bound (i.e. restrained, rigid and tense) or free (i.e. flowing, fluid and relaxed) a movement is.

The relationship category is based on with whom and with what the students' movements interact and takes two dimensions as its starting points. The first is the dimension with other students' movements, based on how they interact with each other, i.e. whether the students execute the movements in front of, beside or behind each other; whether they are far from, at arm's length from or close to one another; whether the movements are above, at the same level as or below one another; and whether the movements take place towards, round or from one another. The second dimension is with the game, in this case the students' movements in relation to the games played, focusing on whether the movements occur far away or close, and if they are copied, meaning executed in the same way and at the same time as the avatar's, or are contrasted, i.e. different from the avatar's.

\section{Data and analysis}

The data used in this study comprises video recordings of students playing Nintendo Wii exergames in PE-lessons in a compulsory school (for children 
aged 7 to 16) in a small Swedish town. The students were offered three types of games: sports, exercise and dance. In total, the videoed material covers three sixty-minute PE lessons, recorded during the autumn of 2012 and in which just over twenty students participated. For the first lesson, the class was divided into four groups who rotated round four stations: badminton, table tennis and two exergames. At one of the exergame stations, the students could choose between sports (Wii Sport) and exercise (Wii Fit Plus) games and at the other station different dance games (Just Dance 1 and 2). In the other two lessons, the students could choose freely between the four stations. One video camera was placed on a tripod at each of the exergame stations, and large TV sets were used for the games. In total, the data from the three lessons totalled 216 minutes and 11 seconds of recorded data.

There are further video recordings of free-choice lessons where two groups of students played exergames over a ten-week period. The free-choice lesson is a form of teaching where for a time the students can go into greater depth into an activity/ subject of their choice from those offered by the school. One group consisted of three boys and the other of four girls, both in separate rooms. When analysing, only those occasions when the students (the three boys and the four girls) chose to play sports games were selected. This was to complement the material on sports games because the students only played two different sports games during the lessons. A video camera was used in each room, each mounted on a tripod. The games were played on TV sets. In total, the data from the free-choice lessons totalled 26 minutes and 46 seconds of sports games.

In this study we have used video observation as a method for examining and analysing students' movements. Jordan and Henderson $(1995,51)$ maintain that video observation removes the gap between 'what people say they do and what they, in fact, do'. Since we were interested in which movements they used when exergaming and not hearing what movements they thought they were using, video was a reasonable tool to employ in this study. The videoed material also made it possible to view the students' movements again and again in order to analyse their various movements on film. This enabled us to simultaneously see what was going on in the game and the students' execution of their movements and thus more thoroughly being able to fill in the Movement Analysis Chart. According to Heath, Hindmarsh and Luff (2010), a further advantage is that the material can be repeatedly shown to, and shared with, other people. The video observation was open (Hastie \& Hay, 2012) in the sense that the students knew they were being filmed during all the lessons.

The study follows the ethical guidelines stated in Swedish law and the students and their parents/guardians were informed of the aims and method of the study. 
The students as well as their parents/guardians have given permission for the filming. We also made it clear that at any point the students could choose not to be filmed. All the involved participants consented to being filmed for the study.

What do the pupils play when they get to choose? The students' movements during the recorded sequences of the sports games, exercise games, and dance games have been examined using the movement analysis chart drawn up (see Table 1). The length of the three PE-lessons involving exergames, the gender division of the students and the choice of game are shown in Table 2.

Table 2

Summary of the activities, the length of the games and the gender division in the PE-lessons

\begin{tabular}{|c|c|c|c|c|}
\hline & Camera & Activity & Time & $\begin{array}{l}\text { Gender } \\
\text { (girl, boy) }\end{array}$ \\
\hline \multirow{2}{*}{ Lesson 1} & 1 & dance games & $41 \mathrm{~m} 41 \mathrm{sec}$. & girls, boys \\
\hline & 2 & sports game (Bowling) & $19 \mathrm{~m}$ & girls, boys \\
\hline \multirow{3}{*}{ Lesson 2} & 1 & dance games & $46 \mathrm{~m} 33 \mathrm{sec}$. & girls \\
\hline & 2 & sports game (Boxing) & $26 \mathrm{~m} 9 \mathrm{sec}$. & girls \\
\hline & 2 & $\begin{array}{c}\text { exercise games (Obstacle Course, Balance } \\
\text { Bubble, Ski Jump) }\end{array}$ & $14 \mathrm{~m} 53 \mathrm{sec}$. & girls \\
\hline \multirow[t]{2}{*}{ Lesson 3} & 1 & $\begin{array}{l}\text { exercise games (Obstacle Course, Bird's- } \\
\text { Eye Bulls-Eye, Hula Hoop, Ski Slalom, } \\
\text { Snowball Fight, Rhythm Kung Fu) }\end{array}$ & $34 \mathrm{~m} 20 \mathrm{sec}$. & girls \\
\hline & 2 & dance games & $44 \mathrm{~m} 16 \mathrm{sec}$. & girls \\
\hline
\end{tabular}

During the three PE-lessons, the students chose two different sports games: bowling and boxing, which produced two movement analyses (45 $\mathrm{m} 9 \mathrm{sec}$.). There were additionally eight different exercise games: Obstacle Course, Balance Bubble, Ski Jump, Bird's-Eye Bulls-Eye, Hula Hoop, Ski Slalom, Snowball Fight and Rhythm Kung Fu, resulting in eight movement analyses (49 m 13 sec.). Finally, they chose various dances from dance games with different levels of difficulty and effort. During lesson one, eight different dances were done, with twelve girls and one boy taking part. On all but one occasion, four players simultaneously took part. In lesson two, a total of eleven dances were done, by girls only, and in lesson three, nine dances were done, again by girls only. From the above choices, we carried out eight movement analyses (132 m 30 sec.). 
As the three PE-lessons only included two different sports games, we chose to supplement this with six other sports games selected by the students from the free-choice lessons. This was in order to do eight movement analyses for this category as well. These activities resulted in six movement analyses (20 m 11 sec.). The six supplementary analyses, the length of the games, the gender division of the students and the choice of game are shown in Table 3.

Table 3

Summary of the chosen activities, the length of the games and the gender division of the freechoice lessons

\begin{tabular}{lccc}
\hline Film sequence & Activity & Time & Gender (girl/boy) \\
\hline 1 & Table tennis & $2 \mathrm{~m}$ & 2 girls \\
2 & Tennis & $6 \mathrm{~m} 25 \mathrm{sec}$. & 2 girls \\
3 & $4 \mathrm{~m} \mathrm{35} \mathrm{sec.}$ & 2 boys \\
4 & Archery & $5 \mathrm{~m} \mathrm{35} \mathrm{sec.}$ & 3 boys \\
5 & 3-Point Contest (basketball) & $3 \mathrm{~m} 45 \mathrm{sec}$. & 1 boy \\
6 & Sword fighting/fencing & $20 \mathrm{sec}$. & 2 boys \\
\hline
\end{tabular}

\section{Movement analyses of the three types of exergames}

In the study a total of 24 movement analyses of exergaming in PE practice were conducted using the Movement Analysis Chart. The results of the analysis of the students' different movement qualities when exergaming are presented based on the respective games: sports, exercise, and dance. A summary of the students' movements in the three games then follows.

Sports games. One or two players stand in front of the TV screen, each with a hand control in their right or left hand. The idea of the game is to score as many points/goals/hits as possible or to beat the opponent. A prominent feature of these games is competition resulting in rankings and a winner. The movements that are evident in the analysis of the sports games are specified based on the four categories: body, space, effort and relationship.

Body. Focusing on what happens to the students' body movements when they interact with sports games, it is evident that they principally use certain isolated 
body parts or several body parts that work together to execute a movement. For example, in 3-Point Contest (basketball), boxing, golf, tennis and bowling, mainly the arms, trunk and legs perform the movements, while in table tennis, fencing and archery, the forearm and the controller hand are used most. During the sports games, body actions are performed with movements often taking place in one spot, in the form of weight transfer, both forwards and backwards (bowling, basketball, table tennis, golf) but also sideways (tennis, boxing, fencing), and steps on the spot or sometimes standing jumps, for instance boxing or frisbee. In archery, there are no body actions when the student sits down. With regard to body shape, this takes the form of extending and bending the body, for example in bowling, archery, frisbee and tennis. In boxing and fencing, the body also extends and twists and the arms swing. In golf, the students extend, stretch, bend and twist the body while the arms swing, sway and extend in parallel.

Space. Focusing on where the movement happens in space, we find that it is executed in both the personal and the general space. Regarding in what directions the player performs his or her movements, in sports games the movements, both arm and leg, are mostly towards the TV screen. In boxing, tennis and archery, there are also backwards movements. Our analysis shows that in fencing, tennis and frisbee the controller arm is the most active, with the arm moving sometimes forwards, upwards and downwards, and also with an arm movement away from and towards the body. In the sports games, the pathways are primarily straight towards the game, but the student usually stands in the same spot, except for archery, where the player chooses to sit, resulting in no pathways. The extension of the movements varies between wide and narrow in a standing position. The students' bodies are in a middle level, i.e. they are neither up on their toes nor down on their stomach on the floor, and there are few visible changes of level. The students perform predominately sagittal plane movements

Effort. The next step in the analysis is studying how the movement is executed when the students play the sports games. With regard to time, the controller arm's movements are rapid and fleeting, but in archery the movements are slow and relaxed. Looking at with what weight movements are executed, they appear powerful and firm, except for archery, where they are airier and fainter. Regarding space, the movements in table tennis, boxing, archery and fencing demonstrate a straight and distinct trajectory, while the movements in space in tennis can be described as wavy and scattered. Finally, when analysing the flow of the movement in sports games, it is flowing, fluid and relaxed, except for archery, where the movement is restrained, rigid, and tense, i.e. more bound in comparison with the other sports games. 
Relationship. In the analysis of with whom and with what the movements interact, it must be pointed out that there are differences depending on which game is played. In archery, bowling, golf and frisbee, one student plays alone, with the students taking turns to play; the student looks at the game and interacts with the game's avatar. In boxing, tennis, fencing and table tennis, two students play at the same time, standing side by side and looking at the game, and there is interaction with both the avatar and the human opponent. There is no movement between the students, such as moving around each other or changing places. They stand next to each other, roughly at arm's length, and the movements take place at the same height. The students also stand in front of, and close to, the game on the screen. The students copy the avatar's movements while competing against the avatar, or the opponent's avatar. To sum up the analysis see table 4 .

Table 4

Summary of the movement analysis of the sports games

\begin{tabular}{|c|c|c|c|c|}
\hline & $\begin{array}{l}\text { Body } \\
\text { (what) }\end{array}$ & $\begin{array}{l}\text { Space } \\
\text { (where) }\end{array}$ & $\begin{array}{l}\text { Effort } \\
\text { (how) }\end{array}$ & $\begin{array}{l}\text { Relationship } \\
\text { (with whom and } \\
\text { what) }\end{array}$ \\
\hline $\begin{array}{l}\text { Sports } \\
\text { games }\end{array}$ & $\begin{array}{l}\text { body parts: } \\
\text { isolated and } \\
\text { multiple } \\
\text { body action: in } \\
\text { one place, often } \\
\text { with weight } \\
\text { transfer } \\
\text { body shape: } \\
\text { extensions and } \\
\text { bends }\end{array}$ & $\begin{array}{l}\text { space: in the } \\
\text { personal and } \\
\text { general } \\
\text { direction: mostly } \\
\text { forwards and } \\
\text { sideways } \\
\text { pathway: mostly } \\
\text { straight } \\
\text { extension: wide } \\
\text { and narrow in a } \\
\text { standing position } \\
\text { level: middle } \\
\text { plane: mostly in the } \\
\text { sagittal }\end{array}$ & $\begin{array}{l}\text { time: fast and } \\
\text { fleeting } \\
\text { weight: powerful, } \\
\text { firm and clear } \\
\text { space: straight } \\
\text { and distinct } \\
\text { movement } \\
\text { trajectory } \\
\text { flow: flowing, fluid } \\
\text { and relaxed }\end{array}$ & $\begin{array}{l}\text { Interaction with } \\
\text { playing partner/ } \\
\text { opponent since } \\
\text { they stand side by } \\
\text { side and with the } \\
\text { game by copying the } \\
\text { avatar's movements }\end{array}$ \\
\hline
\end{tabular}

In conclusion: the movement qualities used in sport games can be said to be specific, elementary, straight with low intensity in some games, like in archery, and relatively high intensity in others, like boxing.

Exercise games. When playing the exercise games, one student at a time stands in front of the TV screen on a balance board placed vertically or parallel 
to the TV. The idea of the game is to practise mainly balance, body control and certain specific exercises like, for example, yoga. The exercise games also allow the students to carry out different tasks that the game is based around, for instance moving along a multi-surface course, getting past obstacles and reaching a target (Obstacle Course, Balance Bubble, Ski Jump, Bird's-Eye Bulls-Eye, Hula Hoop, Ski Slalom, Snowball Fight and Rhythm Kung Fu). These games are set in a fitness discourse with feedback in the form of points, ranking, calorie consumption and time spent exercising. The students' movement qualities will be described in terms of the aforementioned categories.

Body. Focusing on what happens, we observe that the students lean in different directions using the following body parts: feet, legs, trunk and arms. The executed body actions are in the form of the student training his or her balance; the student stands on the balance board and performs the actions by weight transfer in their feet $/ \mathrm{knees} /$ thighs or using the whole body to initiate and imitate movements in the game in question (Obstacle Course, Balance Bubble, Ski Jump, Bird's-Eye Bulls-Eye, Hula Hoop, Snowball Fight, Ski Slalom and Rhythm Kung Fu). Stepping around the balance board, for example in Obstacle Course, Snowball Fight and Hula Hoop, is another body action the students execute. The body shapes that are most evident are extending, stretching, twisting, bending and the upward lift of the body (Balance Bubble, Ski Jump, Bird's-Eye Bulls-Eye, Hula Hoop and Ski Slalom) and also knee bends (Obstacle Course, for example).

Space. Our analysis of where in space the body movements take place in the exercise games shows that the students are principally in the personal space. The general space is limited since the students are standing in more or less the same place. The movement direction is shown to be mostly forwards towards the TV screen. In some games, there can be sideways (Balance Bubble, Bird'sEye Bulls-Eye and Ski Slalom), occasionally upwards (Ski Jump) or downwards (Rhythm Kung Fu) movements in relation to the original position. There are no pathways since the player is standing on the balance board. The extension of the movement varies from narrow to wide (Hula Hoop and Snowball Fight), from short to long (Obstacle Course, Balance Bubble and Ski Slalom), depending on the movements executed to maintain balance and body control during the movement itself and to successfully carry out the activity the game involves. In relation to the space and the original position, there are most often medium-level movements, though in some cases an upwards movement where the student extends the whole body and goes up on tiptoe. However, there are neither any low-level body positions nor movements during the exercise games. There are principally frontal plane movements and in some individual cases sagittal plane movements during Ski Slalom, Hula Hoop and Rhythm Kung Fu. 
Effort. Looking at how movements are executed in exercise games, we see that movements in time are quick and fleeting (Obstacle Course, Ski Jump, Bird'sEye Bulls-Eye, Hula Hoop, Ski Slalom and Rhythm Kung Fu) and slow and relaxed (Balance Bubble and Hula Hoop). Our analysis of weight has shown that some students' movements are firm and clear (Rhythm Kung Fu, Snowball Fight, Ski Jump and Obstacle Course), while others' executed movements are fainter and more indistinct (Balance Bubble, Ski Slalom, Hula Hoop and Bird'sEye Bulls-Eye). Their movements in space can be described as both straight and distinct (Ski Jump and Rhythm Kung Fu), but the games mainly produce wavy and scattered movements (Balance Bubble, Obstacle Course, Bird's-Eye Bulls-Eye, Hula Hoop and Ski Slalom). The movement flow varies from student to student and also in relation to the game played. It is apparent that the movements are restrained, rigid and tense when playing, for example, Snowball Fight, Balance Bubble and Ski Jump, but more flowing, fluid and relaxed during Bird'sEye Bulls-Eye and Hula Hoop.

Relationship. The analysis of with whom or with what the movements interact in the exercise games shows this solely takes place in relation to the game the student is standing in front of. The movements take place in the students' personal space, fairly close to the TV. The movements demonstrated in the game are copied, and it is evident that there is no contrasting. In addition, the particular movement is practised by balancing and focusing on body control through student-game interaction. To make an overview of the analysis of movement qualities in exercise games, see table 5 . 
Table 5

Summary of the movement analysis of the exercise games

\begin{tabular}{llll}
\hline $\begin{array}{l}\text { Body } \\
\text { (what) }\end{array}$ & $\begin{array}{l}\text { Space } \\
\text { (where) }\end{array}$ & $\begin{array}{l}\text { Effort } \\
\text { (how) }\end{array}$ & $\begin{array}{l}\text { Relationship } \\
\text { (with whom } \\
\text { and what) }\end{array}$ \\
\hline time: quick & \\
and fleeting, \\
also slow and \\
relaxed
\end{tabular}

In conclusion: the movement qualities used in exercise games can be said to be restricted, stationary in terms of space with a focus on balance and body control.

Dance games. Two to four players at the same time (frequently four in this data set) stand in front of the TV screen, each holding a hand control. The idea of the game is to mimic the various dance steps on the screen. Depending on which dance is selected, there may be one avatar or a pair or four on the screen. The dances have different levels of difficulty and effort, which is displayed on the screen. The dancers score points and the winner is crowned for each dance. The dance games also involve a competition discourse. The students' analysed movement qualities are specified based on the above categories. 
Body. Focusing on what happens to the body movements when the students interact with the dance games, it is evident that many body parts are involved. The dance games offer numerous different rhythms, dance steps and movements involving many parts of the body, at any rate when the on-screen avatar is moving. Our analysis of the students' movements shows that many parts of the body are used, such as the head, trunk, arms (including hands), legs and feet. Arm movements, principally the controller arm/hand, are the most prominent but also the trunk, legs and feet are used in the various dance movements. The body actions are mostly executed through weight transfer, stepping and one-legged or standing jumps, the movements of which are done with balance. The body shapes that are evident are trunk extensions, trunk stretches, trunk twists and trunk bends and the swinging and swaying of the arms.

Space. The analysis of where in space the movements are executed when students play dance games shows that they move in both the personal and the general space. The players move in forward, sideways, upwards and downwards directions but also 360 degrees around. There are few pathways in space since the student mainly stands in the same place in front of the TV screen; however, there are some small forward or sideways foot movements or, for example, with a 360-degree pirouette on its own axis. There are also pathways when two players change places with each other or move in front of, or behind, each other during the dance. The extension of the movements varies from narrow to wide and from short (hunched up) to long (stretching on tiptoe). There are mostly mediumlevel movements with a tendency to extend the body upwards and then often on tiptoe and bending the body down or crouching into a squat. Sometimes there are also fully extended (high-level) movements that become low-level movements when the student kneels and executes the movements demonstrated by the avatar. There are principally frontal plane movements, but also horizontal (arm waving and trunk movements) and sagittal plane movements (movement forwards or backwards).

Effort. The analysis of how the movements were executed when the students played the dance games shows that the effort levels of the games are significant, i.e. the type of dance affects the degree of effort. The students' movements varied in time and might be slow, relaxed and continuous, or quick, fleeting and staccato, very much depending on the game played. The dances are different and from various music genres. With regard to weight, the effort of the players' body movements may vary from airy, faint and indistinct to powerful, firm and clear, depending on the dance but also on what experience the performer has of dance movements or how much he or she 'goes for it' when dancing. The movements in space are often wavy and scattered but are sometimes straight and distinct when the dance style has robotic movements. The flow of the movements can be 
described as restrained, rigid and tense, and at other times more like 'letting go' and thus can be analysed as flowing, fluid and relaxed.

Relationship. The analysis of with whom or with what the movements in the dance games interact shows that this is between the students and the game's avatar(s). The students usually stand beside one another, with two players standing slightly in front of the other two so as to maintain space and room to move in. They are quite close together (at arm's length and at the same height) when doing the movements. Sometimes they move past one another or cross back and forth and sometimes they go round another player. They position themselves in front of and fairly close to the TV screen since they are mimicking or contrasting the movements, all depending on the type of dance. The different steps and movements are practised but the importance of competitiveness, with the number of points and sweat drops and the winner being announced at the end of the dance, is also reflected in this game. In table 6 we have made a summary of the movement analysis.

Table 6

Summary of the movement analysis of the dance games

\begin{tabular}{|c|c|c|c|c|}
\hline & $\begin{array}{l}\text { Body } \\
\text { (what) }\end{array}$ & $\begin{array}{l}\text { Space } \\
\text { (where) }\end{array}$ & $\begin{array}{l}\text { Effort } \\
\text { (how) }\end{array}$ & $\begin{array}{l}\text { Relationship } \\
\text { (with whom and } \\
\text { what) }\end{array}$ \\
\hline $\begin{array}{l}\text { Dance } \\
\text { games }\end{array}$ & $\begin{array}{l}\text { body parts: } \\
\text { arm and hand } \\
\text { movements, plus } \\
\text { trunk, legs and } \\
\text { feet } \\
\text { body actions: weight } \\
\text { transfer, stepping, } \\
\text { one-legged/ } \\
\text { standing jump } \\
\text { body shape: trunk } \\
\text { extensions, trunk } \\
\text { stretches, trunk } \\
\text { twists and trunk } \\
\text { bends, arm } \\
\text { swinging and } \\
\text { swaying }\end{array}$ & $\begin{array}{l}\text { space: in the } \\
\text { personal and } \\
\text { general } \\
\text { direction: forwards, } \\
\text { sideways, up, } \\
\text { down and round } \\
\text { pathway: straight } \\
\text { and circular in the } \\
\text { form of rotations } \\
\text { extension: narrow } \\
\text { to wide } \\
\text { level: all } \\
\text { three: low, medium } \\
\text { and high } \\
\text { plane: frontal, } \\
\text { horizontal and } \\
\text { sagittal }\end{array}$ & $\begin{array}{l}\text { time: slow, relaxed } \\
\text { and continuous } \\
\text { or quick, fleeting } \\
\text { and staccato } \\
\text { weight: from } \\
\text { airy, faint and } \\
\text { indistinct to } \\
\text { powerful, firm } \\
\text { and clear } \\
\text { space: wavy and } \\
\text { scattered } \\
\text { flow: restrained, } \\
\text { rigid and tense } \\
\text { but also flowing, } \\
\text { fluid and relaxed }\end{array}$ & $\begin{array}{l}\text { Interacts with the } \\
\text { game, fellow players } \\
\text { and dance partner; } \\
\text { stand close beside } \\
\text { one another at arm's } \\
\text { length, mimicking } \\
\text { dance steps and } \\
\text { movements; } \\
\text { standing in front } \\
\text { of the game on the } \\
\text { screen but also in } \\
\text { front of and behind } \\
\text { other dancers }\end{array}$ \\
\hline
\end{tabular}


In conclusion: the movement qualities used in dance games can be said to be varied in space, direction, level and plane, and developed using large movements in different planes involving also rhythm and interaction.

Comparison of students' use of different movement qualities in the three types of games. For the three lessons when the students were allowed to choose the games, the dance games were the most frequently played, followed by the exercise games, and last the sports games.

When comparing the students' movements when playing the three types of games, the movement analysis helps to identify similarities and differences. Regarding the movements identified using the Movement Analysis Chart and practised by the students in the different games, when it comes to the body category, the movements they use are most developed and varied in the dance games. In the space category, the students' movements demonstrate the greatest variation of space, direction, pathway, level and plane during the dance games. In the exercise games, the balance board is used to practise in particular balance and body control, which is not the case with the other two types of games. As for the effort category, the sports games differ since the students here use the least complex movement qualities in terms of time, weight, space and flow of body movement. Finally, looking at the relationship category, in the exercise games the students' movements only interact with the game, whereas the students interact both with the avatar(s) and with fellow players/opponents or with fellow players and dance partners in the other two types of games.

The findings of the study indicate that when students play exergames, a variety of body movements and qualities are used, depending on the character of the game. The study also shows that the students while playing dance games use a wider variety of movement qualities than in the sport and exercise games. In the dance and sport games the students also interact more with each other and not only with the game as in the exercise games. An interesting follow up to this study would be to compare exergaming with other activities in PE in terms of movement qualities using the Movement Analysis Chart. Even though it was not part of this study, during the videotaped lessons other activities were table tennis and badminton, and our impression was that the students in these activities not were more active or used more complex movement qualities than the ones exergaming. In relation to the dance games the sense was that they used less variation of movement qualities in table tennis and badminton, but this, of course, must be investigated further. 


\section{Discussion}

In the light of the introduction of a new teaching aid like exergames, and the publication of a new curriculum in Sweden, this article has aimed to highlight students' body movements, with a focus on the use of different movement qualities, when exergaming in PE-lessons. To capture the students' execution of their movements, we drew inspiration from LMA and sociocultural ideas. This has been done developing and using an LMA-inspired Movement Analysis Chart.

Before conducting this study on exergames in PE-lessons, we asked ourselves which movements do the students practise and execute, and, by extension, what is the educational value of exergaming in terms of movement qualities? And how can a Movement Analysis Chart help us to educate and guide students doing PE? Using an analysis chart and taking inspiration from LMA, we have been able to explicate and put into words various aspects of the movements the students practise in this context. Articulating the students' movements can be seen as a way of helping teachers to teach and to evaluate students' movement qualities in PE. In this way the educational value of the exergames can be discussed in terms of movement qualities, and not only in terms of the physiological or psychological effects of exergaming in general as previous research have highlighted. Hence, a wider picture of the benefits and risks of introducing exergames in PE can be achieved.

In this vein the educationalist John Dewey (1938) argues that it is important that teachers have a clear objective of what students should be taught and educated about. He also maintains that the activity itself should not be exaggerated, but stresses the importance of designing teaching with clear educational goals. With this in mind we would argue that before exposing students to new learning activities, such as when introducing new teaching tools or materials like exergames, teachers must carefully consider the consequences of doing so (Öhman et al. 2014). Thus, a PE-teacher should reflect upon the choice of movement activities and potential aids in relation to the objectives of the subject, the content of the lessons and of course his or her students. In other words, didactic reflection is of utmost importance, and for this a thorough knowledge base is necessary. Our study can shed light on the issue of movement qualities in PE and in consequence what movement qualities students develop while exergaming.

In relation to exergames Trout and Christie (2007) strongly maintain, and we agree, that interactive games must not replace PE, but should rather be seen as a potential addition to other pedagogical practices. At the same time, exergames could be a way to reach students that not value traditional PE 
practices, as Wright (2004: 2) states, that '[if] schools ignore the context in which students live and their experiences, knowledge, capacities and concerns, they run the risk of being increasingly irrelevant for many young people'. Young et al. (2012) as well as Trout and Christie (2007) further maintain that it is important that there is a teacher present to guide the students in their learning so that the interactive games do not take over from the teaching and with that replace the teacher (Vander Schee \& Boyles 2010).

Even if our own study is about how students interact with the game and other students rather than interacting with the teacher, we would argue that exergames potentially can become a teaching resource and not only an activity where 'throwing in the exergame' just replaces 'throwing in the ball'. Instead, introducing new technology into teaching requires extensive research and planning, whereby the teacher should consider how technology could be used pedagogically to complement his or her teaching in order to achieve the curriculum objectives, in this case regarding the development of movement qualities.

\section{References}

Amade-Escot, C. (2000). The contribution of two research program on teaching content. "Pedagogical content knowledge" and "Didactics of physical education". Journal of Teaching in Physical Education, 20, 78-101

Allison, P. C. (1990). Classroom teachers' observations of physical education lessons. Journal of Teaching in Physical Education, 9, 272-283

Azzarito, L. \& Solomon, M. (2006). A feminist post-structuralist view on student bodies in physical education: sites of compliance, resistance and transformation. Journal of Teaching in Physical Education, 25, 200-226

Biddiss, E., \& Irwin, J. (2010). Active video games to promote physical activity in children and youth: a systematic review. Archives of Pediatrics \& Adolescent Medicine, 164, 664-672

Brubaker, B. (2006) Teachers join the dance, dance revolution: educators begin training to use the exercise video game. Available on line at: http://www. redorbit.com/news/scifigaming/424434/teachers_join_the_dance_dance_ revolution/ (accessed 20 March 2008) 
Carvalhal, M. M., Padez, M. C., Moreira, P. A., \& Rosado, V. M. (2007). Overweight and obesity related to activities in Portuguese children, 7-9 years. European Journal of Public Health, 17, 42-46

Chen, A. \& Ennis, C. (2004). Goals, interest and learning in physical education. The Journal of Education research, 97, 329-339

De Lisi, R., \& Wolford, J. L. (2002). Improving children's mental rotation accuracy with computer game playing. The Journal of Genetic Psychology: Research and Theory on Human Development, 163, 272-282

Dewey, J. (1938). Experience and education. New York: Harper Collins

Ennis, C. D. (2006). Curriculum: forming and reshaping the vision of physical education in a high need, low demand world of schools. Quest, 58, 41-59

Ennis, C. D. (2013). Implications of exergaming for the physical education curriculum in the 21 st century. Journal of Sport and Health Science, 2, 152-157

Fagrell, B., Larsson, H. \& Redelius, K. (2012). The game within the game: girls' underperforming position in physical education. Gender and Education, 24, $101-118$

Fery, Y.-A., \& Ponserre, S. (2001). Enhancing the control of force in putting by video game training. Ergonomic, 44, 1025-1037.

Fogel, V., Miltenberger, R. G., Graves, R., \& Koehler, S. (2010). The effects of exergaming on physical activity among inactive children in a physical education classrom. Journal of Applied Bebaviour Analysis, 43, 591-600

Foroud, A., \& Whishaw, I. Q. (2006). Changes in the kinematic structure and non-kinematic features of movements during skilled reaching after stroke: A Laban Movement Analysis in two case studies. Journal of Neurosience Methods, $158,137-149$

Gao, Z., Hannan P., Xiang, P., Stodden, D. F., Valdez, V. E. (2013). Urban Latino children's physical health and academic performance: effect of active video game based exercise. American Journal of Preventive Medicine, 44, 240-246

Gao, Z., Zhang, T. \& Stodden, D. (2013). Children's physical activity levels and phychological correlates in interactive dance versus aerobic dance. Journal of Sport and Health Sciences, 2, 146-151 
Gard, M. \& Wright, J. (2001). Managing uncertainy: obesity discourses and physical education in a risk society. Studies in Philosophy and Education, 20, 535-549

Gard, M. (2006). More art than science? Boys, masculinities and physical education research. In D. Kirk, D. Macdonald, M. O'Sullivan, D. Kirk, D. Macdonald, \& M. O'Sullivan (Eds.), The handbook of physical education (pp. 784795). London: Routledge

Graf, D. L., Pratt, L. V., Hester, C. N., \& Short, K. R. (2009). Playing active video games increases energy expenditure in children. Pediatrics, 124, 534-540

Guy, S., Ratzki-Leewing, A., \& Gwadry-Sridhar, F. (2011). Moving beyond the stigma: systematic review of video games and their potential to combat obesity. International Journal of Hypertension, 2011, 1-13

Hastie, P., \& Hay, P. (2012b). Qualitative approaches. In K. Armour, \& D. Macdonald (Eds.), Research methods in physical education and youth sport (pp. 7994). Milton Park, Abingdon, Oxon: Routledge

Hayes, E., \& Silberman, L. (2007). Incorporating video games into physical education. Journal of Physical Education, Recreation \& Dance, 78, 18-24

Heath, C., Hindmarsh, J., \& Luff, P. (2010). Video in qualitative research: analysing social interaction in everyday life. Los Angeles: SAGE

Jordan, B., \& Henderson, A. (1995). Interaction analysis: foundations and practice. The Journal of Learning Sciences, 4, 39-103

Ko, S. (2002). An empirical analysis of children's thinking and learning using a computer game context. Educational Physchology, 22, 219-233

Kirk, D. (2001). Schooling bodies: School practice and public discourse. Leicester, UK: Leicester University Press

Laban, R. V. (1988). Modern educational dance (4rd ed.). Plymouth: Northcote House

Langton, T. W. (2007). Applying Laban's Movement Framework in Elementary Physical Education. JOPERD, 79, 17-24, 39-40

Larsson, H. \& Quennerstedt, M. (2012). Understanding Movement: A Sociocultural Approach to Exploring Moving Humans. Quest, 64, 283-298 
Levy, J. A., \& Duke, M. P. (2003). The use of Laban movement analysis in the study of personality, emotional state and movement style: an exploratory investigation of the veridicality of "body language". Individual Differences Research, 1, 39-63

Lwin, M., \& Malik, S. (2012). The efficacy of exergames-incorporated physical education lessons in influencing drivers of physical activity: a comparison of children and pre-adolescents. Psychology of Sport and Excercise, 13, 756-760

Maddison, R., Mhurchu, C. N., Jull, A., Jiang, Y., Prapavessis, H., \& Rodgers, A. (2007). Energy expended playing video console games: An opportunity to increase children's physical activity? Pediatric Exercise Science, 19, 334-343

Meckbach, J. \& Söderström, S. (2002). “Kärt barn har många namn”: idrott \& hälsa i skolan. I: L-M. Engström \& K. Redelius (Eds.), Pedagogiska perspektiv på idrott (pp. 209-239). Stockholm: HLS förlag

Meckbach, J., Gibbs, B., Almqvist, J., Öhman, M. \& Quennerstedt, M. (2013). Exergames as a teaching tool in Physical Education? Sport Science Review, 22, 369-385

Millington, B. (2009). Wii has never been modern: 'Active' video games and the 'conduct of conduct'. New Media Society, 11, 621-640

Murray, N. R. \& Lathrop, A. H. (2005). Seeing with understanding: Observing movement for effective pedagogy. Physical and Health Education Journal, spring2005, 12-18

Ni Mhurchu, C., Maddison, R., Jiang, Y., Jull, A., Prapavessis, H. \& Rodgers, A. (2008). Couch potatoes to jumping beans: A pilot study of the effect of active video games on physical activity in children. International Journal of Behavioral Nutrition and Physical Activity, 5, doi:10.1186/1479-5868-5-8

Nyberg, G. \& Larsson, H. (2012). Exploring 'what' to learn in physical education. Physical Education and Sport Pedagogy, pp. 123-135, iFirst Article, DOI: 10.1080/17408989.2012.726982

Paechter, C. \& Head, J. (1996). Gender, identity, status, and the body. Gender and Education, 8, 21-29 
Papastergiou, M. (2009). Exploring the potential of computer and video games for health and physical education: A literature review. Computer \& Education, 53, 603-622

Parteli, L. (1995). Aesthetic listening: Contributions of dance/movement therapy to the psychic understanding of motor stereotypes and distortions in autism and psychosis in childhood and adolescence. The Arts in Psychotherapy, 22, 241-247

Quennerstedt, M., Almqvist, J. \& Öhman, M. (2012). Keep Your Eye on the Ball: Investigating Artifacts-in-Use in Physical Education. Interchange: A Quarterly Review of Education, 42, 287-305.

Quennerstedt, M., Almqvist, J., Meckbach, J., \& Öhman, M. (2014). Why do Wii teach physical education in school? Swedish Journal of Sport Research, 2, 55-81

Shasek, J. (2004). Exerlearning: Movement, fitness, dance, and learning. Unpublished report, RedOctane, Sunnyvale, CA.

Sheehan, D. P. \& Katz, L. (2013). The effects of a daily, 6-week exergaming curriculum on balance in fourth grade children. Journal of Sport and Health Science, 2, 131-137

Silverman, S. \& Subramaniam, P. R. (1999). Student attitude toward physical education and physical activity: a review of measurement issues and outcomes. Journal of Teaching in Physical Education, 19, 97-125

Skoning, S. N. (2008). Movement and dance in the inclusive classroom. TEACHING Exceptional Children Plus. 4(6) Article 2. Retrieved January 12, 2014, from http://escholarship.bc.edu/education/tecplus/vol4/iss6/art2

Song, H., Peng, W. \& Lee, K. M. (2011). Promoting Exercise Self-Efficacy with an Exergame. Journal of Health Communication:International Perspective, 16, 148-162

Sun, H. (2013). Impact of exergames on physical activity and motivation in elementary school students: A follow-up study. Journal of Sport and Health Science, 2, 138-145

Swaminathan, D., Thornburg, H., Mumford, J., Rajko, S., James, J., Ingalls, T., et al. (2009). A dynamic bayesian approach to computational Laban shape quality analysis. Advances in Human-Computer Interaction, 2009, 1-17 
Swedish National Agency for Education (2011) Läroplan för grundskolan, förskoleklassen och fritidshemmet. [Curriculum for compulsory school, preschool and youth leisure centre 2011.] Stockholm: Fritzes

Trout, J., \& Christie, B. (2007). Interactive video games in physical education. The Journal of Physical Education, Recreation and Dance, 78, 29-45

Unnithan, V. B., Houser, W., \& Fernhall, B. (2006). Evaluation of the energy costs of playing a dance simulation video game in overweight and non-overweight children and adolescents. International Journal of Sports Medicine, 27, 804-809

Vander Schee, C. \& Boyles, D. (2010). 'Exergaming,' corporate interests and the crisis discourse of childhood obesity. Sport, Education and Society, 15, 169-185

Vasey, P. L., Foroud, A., Duckworth, N., \& Kovacovsky, S. D. (2006). Male-female and female-female mounting in Japanese macaques: a comparative study of posture and movement. Archives of Sexual Behaviour, 35, 117-128

Wallian, N. \& Chang, C.W. (2006). Development and learning of motor skill competencies. In D. Kirk, D. Macdonald, M. O'Sullivan, D. Kirk, D. Macdonald, \& M. O'Sullivan (Eds.), The bandbook of physical education (pp. 292-311). London: Routledge

Whitehead, M. (2007). Physical literacy: philosophical considerations in relation to developing a sense of self, universality and propositional knowledge. Sport, Ethics and Philosophy, 1, 281-298

Webb, L., Quennerstedt, M. \& Öhman, M. (2008). Healthy bodies: construction of the body and health in physical education. Sport, Education and Society, 13, $353-372$

Weiller Abels, K., \& Bridges, J. (2011). Movement education framework (MEF) made EZ! Strategies: A Journal for Physical and Sport Educators, 25, 8-10

Wright, J. (2004). Critical inquiry and problem solving in physical education. In J. Wright, L. Burrows \& D. MacDonald. (Eds.), Critical inquiry and problem-solving in physical education (pp. 3-15). London: Routledge

Young, M. F., Slota, S., Cutter, A. B., Jalette, G., Mullin, G., Lai, B., et al. (2012). Our princess is in another castle: a review of trends in serious gaming for education. Review of Educational Research, 82, 61-89 
Öhman, M., Almqvist, J., Meckbach, J. \& Quennerstedt, M. (2014). Competing for ideal bodies: A study of exergames used as teaching aids in schools. Critical Public Health, 24, 115-132

Jane MECKBACH, PhD in pedagogy and is associate professor at The Swedish School of Sport and Health Sciences (GIH) in Stockholm, Sweden, where she has been for the last 20 years. She is also Dean of the faculty Board at GIH. Her current research areas include teacher training and physical education from a pedagogical and gender perspectives but also young coachers in education. In her research, question of gender, artefacts, subject content and learning processes within educational practice have been prominent.

\section{Corresponding address:}

Jane Meckbach

The Swedish School of Sport and Health Sciences, GIH

Box 5626, SE-114 86 Stockholm, Sweden

E-mail: jane.meckbach@gih.se

Béatrice GIBBS, PhL in sport science and senior lecturer in physical education and health in an upper secondary school where she has been for sex years. The aim of her research project was to investigate student's movement qualities when practice dance exergames which was used as teaching aids in dance education in physical education and health in upper secondary school. She is also a researcher at Örebro University. She can be contacted at: beatrice.gibbs@edu.haninge.se

Jonas ALMQVIST, PhD is associate professor of Curriculum Studies at Uppsala University in Sweden. He earned his PhD in Education at the same university. In his research career he has studied meaning making in educational settings with a special focus on the use of educational technology. Most of his research has been concentrated on teaching and learning in science education classrooms, but also includes an interest in meaning making processes in Physical Education and Health. He regularly presents his research at scientific conferences and publishes in journals in the fields of education, science education and physical education. He can be contacted at: jonas.almqvist@edu.uu.se

Mikael QUENNERSTEDT, PhD is professor in sport science at the School of Health and Medical Sciences, Örebro University, Sweden. Quennerstedt's main area of research is within teaching and learning in physical education, and in health education. In his research, questions of health, body, gender, artefacts, subject content, learning processes and governing processes within educational practices have been prominent. He can be contacted at: mikael.quennerstedt@oru.se 